\title{
BERWALD TYPE INEQUALITY FOR EXTREMAL UNIVERSAL INTEGRALS BASED ON $(\alpha, m)$-CONCAVE FUNCTION
}

\author{
Ya-Zhi Song, XiaO-Qiu Song, Dong-Qing Li And Tian Yue
}

Abstract. The aim of this work is to show a Berwald type inequality for the extremal universal integrals based on $(\alpha, m)$ concave function. Some examples are given to illustrate the validity of these inequalities.

Mathematics subject classification (2010): 03E72, 28B15, 28E10, 26D10. tion.

Keywords and phrases: Berwald type inequality, Extremal universal integrals, $(\alpha, \mathrm{m})$-concave func-

\section{REFERENCES}

[1] M. Sugeno, Theory of fuzzy integrals and its applications, Ph.D. Dissertation, Tokyo Institute of Technology, Meguro-ku, Tokyo, 1974.

[2] R. Mesiar, Choquet-like integrals, Journal of Mathematical Analysis and Applications, 194, 2 (1995), 477-488.

[3] N. SHILKRET, Maxitive measure and integration, Indagationes mathematicae, 74, 1 (1971), 109-116.

[4] S. Weber, $\perp$-Decomposable Measures and Integrals for Archimedean t-Conorms $\perp$, Fuzzy Sets and Systems, 101, 1 (1984), 114-138.

[5] H. Ichihashi And H. Tanaka And K. Asai, Fuzzy Integrals Based on Pseudo-additions and Multiplications, Journal of Mathematical Analysis and Applications, 130, 2 (1988), 354-364.

[6] E. P. Klement And R. Mesiar And E. PAP, A Universal Integral as Common Frame for Choquet and Sugeno Integral, IEEE transactions on fuzzy systems, 18, 1 (2010), 178-187.

[7] J. E. PeČarić and F. Proschan and Y. L. Tong, Convex Functions, Partial Orderings, and Statistical Applications, Academic Press. Inc. Boston, San Diego, New York, 1992.

[8] H. Agahi ANd R. Mesiar And Y. OuYAng And E. PAP And M. ŠTrboja, Berwald type inequality for Sugeno integral, Applied Mathematics and Computation, 271, 8 (2010), 4100-4108.

[9] H. Agahi and A. Mohammadpour And R. Mesiar and S. M. Vaezpour, Useful tools for non-linear systems: Several non-linear integral inequalities, Knowledge-Based Systems, 49 (2013), $73-80$.

[10] V. G. Mihes An, A generalization of the convexity, Seminar on Functional Equations, Approximation Convexity, Cluj-Napoca, Romania, 1993.

[11] Z. Y. WANG AND G. J. KLIR, Generalized Measure Theory, Springer, New York, 2008.

[12] G. Choquet, Theory of capacities, Annales de Linstitut Fourier (Grenoble), 5 (1953), 131-295.

[13] D. Denneberg, Non-additive measure and integral, Kluwer Academic Publishers, Dordrecht, 1994.

[14] E. PAP, Handbook of Measure Theory, Elsevier Science, Amsterdam, 2002.

[15] M. Sugeno And T. Murofushi, Pseudo-additive measures and integrals, Journal of Mathematical Analysis and Applications, 8, 1 (1987), 109-116.

[16] E. PAP, Null-Additive Set Functions, Kluwer Academic Publishers, Dordrecht Boston London, 1995.

[17] F. Durante and C. Sempi, Semicopulae, Kybernetika, 41, 3 (2005), 315-328.

[18] F. SuÁrez García And P. Gil Álvarez, Two families of fuzzy integrals, Fuzzy Sets and Systems, 18, 1 (1986), 67-81.

[19] S. Weber, Two integrals and some modified versions: critical remarks, Fuzzy Sets and Systems, 20, 1 (1986), 97-105. 